\title{
Research on Time and Spatial Variability of Soil pH in Sanmenxia Planted Tobacco Area
}

\author{
Hongbo Qiao ${ }^{1}$, Gao Rui ${ }^{1}$, Zhang Hui ${ }^{1}$, Yanchun $\mathrm{Chen}^{2}$, and Yongshi $\mathrm{Su}^{2}$ \\ ${ }^{1}$ College of information and management science, Henan agricultural university, \\ Zhenzhou 450002, Henan, China \\ ${ }^{2}$ Sanmenxia Filiale Of Henan Tobacco Company, Sanmenxia, 472000, Henan, China
}

\begin{abstract}
Geostatistics combined with GIS spatial technology was applied to analyze the time and spatial variability of $\mathrm{pH}$ in topsoil $(0-20 \mathrm{~cm})$ for planted tobacco region in Sanmenxia district. The results indicated that the $\mathrm{pH}$ value range form 6.5 to 8.8 and meet to the need of produce high quality tobacco, but the $\mathrm{pH}$ value of partial region is high. The $\mathrm{pH}$ value accord with logarithm normal distribution, variance coefficient is $15.2 \%$ and $4.5 \%$ of 2002 and 2007 year respectively. The semivariogram of $\mathrm{pH}$ was best described by the exponential model and spatial heterogeneity of $\mathrm{pH}$ were $55.77 \mathrm{~km}$ and $92.39 \mathrm{~km}$. The Kriging interpolated method was applied to calculated the unobserved points and was used to generate the spatial and discrepancy map, analyzed the reason of the $\mathrm{pH}$ value increase and the method to improve soil. The research supply important method of the Sanmenxia high quality tobacco produce.
\end{abstract}

Keywords: soil pH; semivariance; spatial variability; GIS; Kriging interpolated method.

\section{Introduction}

Soil $\mathrm{pH}$ on soil fertility and a great influence on the effectiveness of nutrients, in the case at low $\mathrm{pH}$ value, $\mathrm{P}, \mathrm{Ca}, \mathrm{Mg}$ reduced the effectiveness of nutrients, on the contrary at high $\mathrm{pH}$ values, the micronutrient $\mathrm{Fe}, \mathrm{Mn}, \mathrm{B}$ for the crops of the state can not absorb. Tobacco on soil $\mathrm{pH}$ highly adaptive, in the $\mathrm{pH} 3.5 \sim 9.0$ of the soil can grow normally, and the complete life cycle. However, the quality of flue-cured tobacco is in a certain range of $\mathrm{pH}$ values of the best, therefore, appropriate to the soil $\mathrm{pH}$ is the basis for the production of high quality flue-cured tobacco (Chen, et al.,1996).

Geostatistics at the beginning of the formation of the 1950's, based on the theoretical research work of France well-known statistician GMatheron in 1960's, some statistician formed a new branch of statistics. Statistics for some workers said: 'Geostatistics is based on regionalized variable theory, in order to function as the main tool for variation to study the spatial distribution of both random and structural, or spatial correlation and dependence of the natural the phenomenon of science' (Wang,1999), temporal and spatial variation of soil nutrients on the full study is accurate soil nutrient management and a reasonable basis for the high-fertilization. With the extensive application of $3 \mathrm{~S}$ technology, the use of statistics and GIS technology to study the spatial variability of soil properties has become one of the hot soil science research (Liu, et al.,2004, Lian, et al.,2008, Wang et al.,2008). 
The use of Geostatistics and GIS (Geographical Information System, GIS) study of spatial variability of tobacco $\mathrm{pH}$ value of not more than is reported, only a few scholars were discussed. Qin studied in Guizhou Province and other tobacco PH value of soil spatial variability characteristics, results showed that the $\mathrm{PH}$ value of a strong spatial correlation, which is mainly affected by structural changes in the impact factor (Qin, et al.,2007). In this paper, the use of GIS and statistical methods to study the area of Sanmenxia tobacco $\mathrm{pH}$ value of temporal and spatial variation of soil characteristics, map soil $\mathrm{pH}$ value of the spatial distribution maps for the Sanmenxia and quality of tobacco production and provide a theoretical basis for soil improvement.

\section{Material and Method}

\subsection{Study Area}

Sanmenxia is the leading tobacco-producing areas of quality, is located in inland midlatitude areas, a warm temperate continental monsoon climate. The annual average temperature $13.2{ }^{\circ} \mathrm{C}$, annual average 2354.3 hours of sunshine, frost-free period of $184 \sim 218$ days, with an average annual rainfall $550 \sim 800 \mathrm{~mm}$, is suitable for the growth of flue-cured tobacco district.

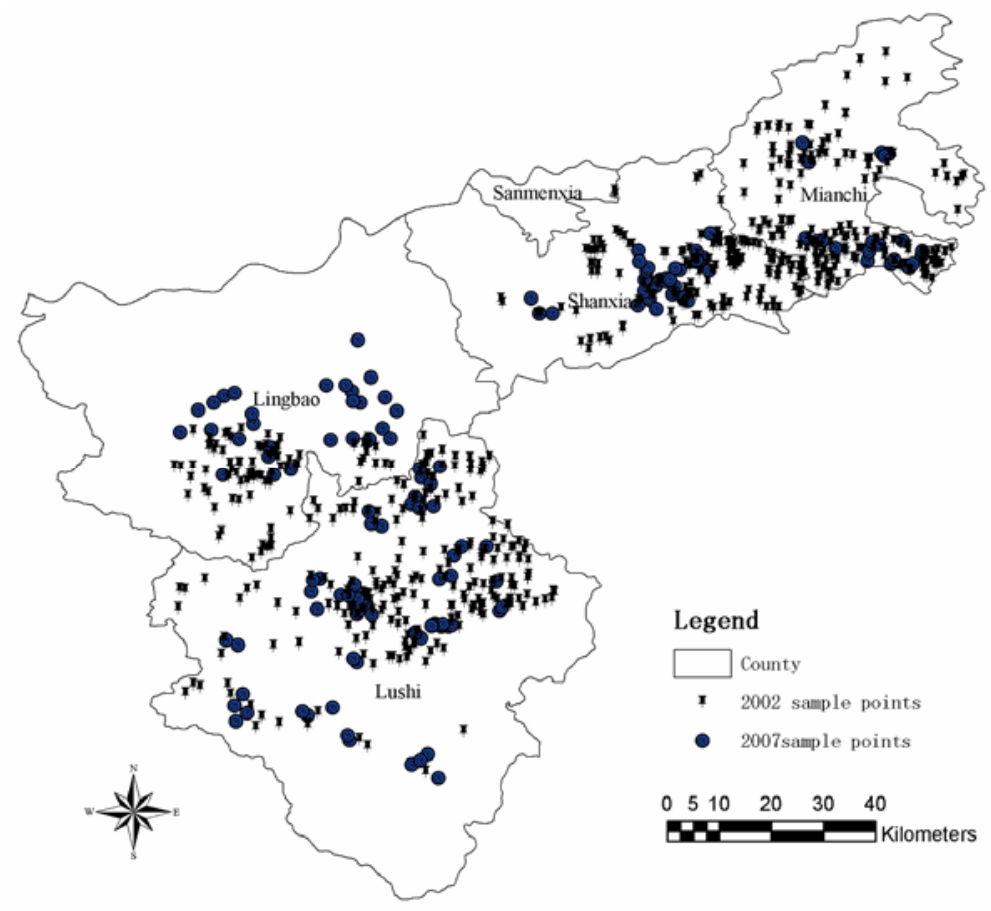

Fig. 1. Sample points in Sanmenxia City 


\subsection{Sample Collection and Analysis}

According to the second national soil survey methods in collecting soil samples. Sanmenxia in the choice of representative tobacco soil, topsoil from $0 \sim 20 \mathrm{~cm}$ soil samples, each sampling point of the area on behalf of $20 \mathrm{hm} 2$, in samples collected at the same time positioning using GPS. 2.5:1 over the use of water and soil-pH extraction method of sample pH. In 2002 and 2007 collecting soil samples 697 and 299, respectively.

\subsection{Data Processing and Analysis}

In this paper, the use of SPSS (11.0) calculated the value of descriptive statistics, GS + (3.0) carried out statistical analysis, the use of ArcGIS (8.3) digital topographic maps and Kriging Interpolation.

\section{Results and Analysis}

\subsection{Sanmenxia Tobacco Distribution of Soil pH Value}

From Table 1, in 2002 tobacco-growing areas of change in soil $\mathrm{pH}$ values between $6.55 \sim 8.55$, with an average of 7.76, distributed in the $6.6 \sim 7.5$ and $7.6 \sim 8.5$, the former level, a total of 251 samples, representing the total number of sampling points $35.9 \%$, after a total of 449 samples, representing $64.1 \%$ of the sampling points. $\mathrm{PH}$ value of 7.5 is usually able to grow high quality tobacco. Accordingly, Sanmenxia has high-quality tobacco sample points is 251 , accounting for the total number of sampling points of $35.9 \%$, Mianchi has the most proportion of suitable points, mounting to $93.5 \%$, followed by Shanxian(accounting for $24.8 \%$ ), Lushi three $(14.9 \%$ ), Lingbao the proportion of the smallest, only $3.7 \%$.

Table 1. The soil $\mathrm{pH}$ value grade and frequency of Sanmenxia Sanmenxia planted tobacco region(2002)

\begin{tabular}{llllllll}
\hline County & $\mathrm{N}$ & Range & $\mathrm{X} \pm \mathrm{S}$ & $5.6 \sim 6.5$ & $6.6 \sim 7.5$ & $7.6 \sim 8.5$ & $8.6 \sim 9.0$ \\
\hline Lingbao & 110 & $7.45 \sim 8.3$ & $7.88 \pm 0.16$ & 0 & 3 & 107 & 0 \\
Shanxian & 157 & $6.55 \sim 8.45$ & $7.74 \pm 0.47$ & 0 & 39 & 118 & 0 \\
Mianchi & 184 & $7.1 \sim 7.7$ & $7.4 \pm 0.13$ & 0 & 172 & 12 & 0 \\
Lushi & 249 & $7.7 \sim 8.55$ & $79.5 \pm 0.34$ & 0 & 37 & 212 & 0 \\
SUM & 700 & $6.55 \sim 8.55$ & & 0 & 251 & 449 & 0 \\
\hline
\end{tabular}

From table 2, the Ph value of Sanmenxia range from 6.6 to 8.8 in 2007, with an average of 7.92, centralized distribution in the $6.6 \sim 7.5$ and $7.6 \sim 8.52$, the former level, a total of 30 samples, accounting for sampling $10 \%$ of the total points, after a total of 239 samples, representing $79.8 \%$ of the sampling points. 
Table 2. The soil $\mathrm{pH}$ value grade and frequency of Sanmenxia Sanmenxia planted tobacco region (2007)

\begin{tabular}{llllllll}
\hline County & $\mathrm{N}$ & Range & $\mathrm{X} \pm \mathrm{S}$ & $5.6 \sim 6.5$ & $6.6 \sim 7.5$ & $7.6 \sim 8.5$ & $8.6 \sim 9.0$ \\
\hline Lingbao & 48 & $7.1 \sim 8.8$ & $7.9 \pm 0.20$ & 0 & 2 & 45 & 1 \\
Shanxian & 45 & $6.6 \sim 8.2$ & $7.8 \pm 0.49$ & 0 & 11 & 31 & 3 \\
Mianchi & 45 & $6.8 \sim 8.1$ & $7.8 \pm 0.32$ & 0 & 6 & 36 & 3 \\
Lushi & 99 & $7.1 \sim 8.8$ & $8.2 \pm 0.37$ & 0 & 11 & 65 & 23 \\
SUM & 299 & $6.6 \sim 8.8$ & & 0 & 30 & 239 & 30 \\
\hline
\end{tabular}

\subsection{Statistical Characteristics of the Soil pH Value}

Data distribution is to use statistical methods to the spatial variability of soil characteristics of the premise of the analysis, only the data in line with the normal distribution only when the statistical analysis to meet assumptions. By the skewness and kurtosis tests indicate that in 2002 and 2007 the determination of soil pH values are in line with the requirements of normal distribution.

Table 3. The description statistics of soil pH in year 2002 and 2007

\begin{tabular}{llllclll}
\hline Year & model & $\mathrm{C}_{0}$ & $\mathrm{C}_{0}+\mathrm{C}$ & $\begin{array}{c}\mathrm{C}_{0} / \mathrm{C}_{0}+\mathrm{C} \\
(\%)\end{array}$ & range $(\mathrm{km})$ & $\mathrm{R}^{2}$ & $\mathrm{RSS}$ \\
\hline 2002 & exponential & 0.198 & 1.048 & 18.1 & 55.77 & 0.713 & 0.133 \\
2007 & exponential & 0.190 & 1.156 & 16.4 & 92.39 & 0.560 & 0.423 \\
\hline
\end{tabular}

\subsection{Soil pH Value of the Spatial Structure Analysis}

Semi-variance in the regionalized variable function is separated from the sample variance on the measure, the semi-variance function model and parameters to select the type of cross validation can be found (Hou, et al., 1998), the result as shown in table 4. 2002 and $2007 \mathrm{pH}$ values of the semi-variance function model fit for the .0713 and .560 on the selected theoretical model to better reflect the spatial structure of soil elements.

The nugget value is far less than the sample spacing on the spatial scale differences in soil properties, which directly limit the size of spatial interpolation accuracy (Zhang, et al., 2003). This study in 2002 and 2007 nugget value of 0.198 and 0.490 , respectively, it showed that experiment error caused by the smaller variation of $\mathrm{pH}$ value in 2002. Sanmenxia soil pH value of spatial distribution is impacted by the topography, soil processes, parent material natural factors.

Nugget value/base value to determine the system variable degree of spatial correlation: If the ratio is less than $25 \%$, indicating that the variable has a strong spatial correlation; if the ratio between $25 \%-75 \%$, indicating moderate spatial correlation; if the ratio is greater than $75 \%$, indicating that the space variables weaker spatial correlation (Cambardella, et al.,1994). Table 4 in 2002 and 2007 nugget value/base value of $18.1 \%$ and $16.4 \%$, with a strong spatial correlation shows that the spatial variation of $\mathrm{pH}$ value caused mainly by parent material, topography and soil processes structural factors, this is accord with the nugget variance analysis results. 
Table 4. Theoretical semivariogram model and corresponding parameters of soil $\mathrm{pH}$ value in year 2002 and 2007

\begin{tabular}{llllllll}
\hline Year & model & $\mathrm{C}_{0}$ & $\mathrm{C}_{0}+\mathrm{C}$ & $\mathrm{C}_{0} / \mathrm{C}_{0}+\mathrm{C}(\%)$ & range $(\mathrm{km})$ & $\mathrm{R}^{2}$ & RSS \\
\hline 2002 & exponential & 0.198 & 1.048 & 18.1 & 55.77 & 0.713 & 0.133 \\
2007 & exponential & 0.190 & 1.156 & 16.4 & 92.39 & 0.560 & 0.423 \\
\hline
\end{tabular}

Range also known as the largest space-related distance, reflecting the range of spatial autocorrelation variable size, in the process of range with spatial correlation, on the contrary does not exist. Table 4 showed that the 2002 and 2007, the range is $55.77 \mathrm{~km}$ and $92.39 \mathrm{~km}$, respectively, that $\mathrm{pH}$ value in the study area have a greater correlation between the extent to reflect the soil parent material, topography and structural factors such as soil type a greater impact. Fitting statistical models to the test by the F reach a significant level, that the sampling density and statistics to meet the needs of the interpolation.

\section{4 pH Value of the Spatial Distribution Characteristics}

According to the semi-variogram model, use of the optimal Kriging interpolation, plot the $\mathrm{pH}$ value spatial distribution map and the differential maps of Sanmenxia city in 2002 and 2007.
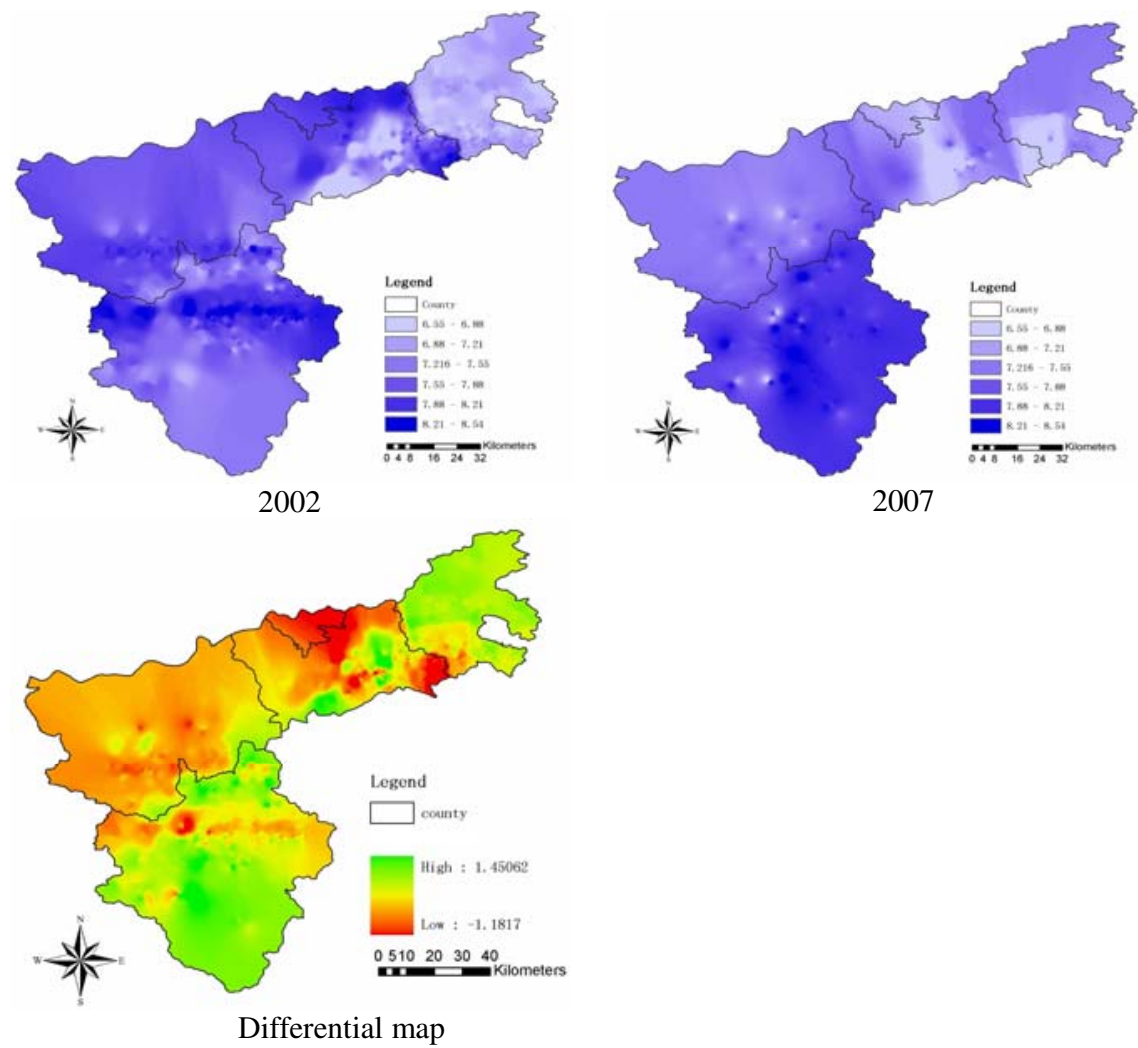

Fig. 2. Kriging estimates and difference for soil $\mathrm{pH}$ in year 2002 and 2007 
In 2002 the soil $\mathrm{pH}$ values spatial distribution of the west, north higher than the east, south, there are some high $\mathrm{pH}$ value of the Lushi. compared to2002, there is the trend of $\mathrm{pH}$ value increased in 2007, that is, the degree of alkaline soil has increased. spatial distribution of $\mathrm{pH}$ as shown in Figure 2, the $\mathrm{pH}$ value of Lushi County Shahe, Panhe and Mianchi Potou has been increasing.

\section{Conclusions}

Suitable soil $\mathrm{pH}$ is conducive to root growth of tobacco, promote the growth of tobacco, enhanced resistance to disease, and improve yield and quality of tobacco (Tang, et al.,1999, Chen, et al.,1996). Therefore, the suitable $\mathrm{pH}$ value of tobacco production on the quality of great significance.

Statistical analysis results show that the $\mathrm{pH}$ value between $6.5 \sim 8.8$ change in the concentration of $6.6 \sim 7.5$ and $7.6 \sim 8.5$ of sanmenxia, meet the needs of high-quality tobacco production, but to some local higher $\mathrm{pH}$ value need to be adjusted. The $\mathrm{pH}$ values obey the lognormal distribution, coefficients of variation were $15.2 \%$ and $4.5 \%$ in 2002 and 2007, respectively,with less variation. The best variance function is experimental model. Soil nugget value/base value were $18.1 \%$ and $16.4 \%$ in 2002 and 2007 , with a strong spatial correlation, the spatial variability of the caused by parent material, topography and soil such factors.

The range of $\mathrm{pH}$ value were $55.77 \mathrm{~km}$ and $92.39 \mathrm{~km}$ in 2002 and 2007 , respectively, that it have a greater correlation, the impact is caused by structural factors such as the soil parent material, topography and soil types.

Use of the optimal Kriging interpolation, plot the $\mathrm{pH}$ value spatial distribution map and the differential maps of Sanmenxia city in 2002 and 2007. As can be seen from the figure, $\mathrm{pH}$ values showed increasing trend, particularly in the eastern and southern part of the Lushi and Mianchi County. The reason may be to increase the amount of chemical fertilizers, natural precipitation decreased but ground water irrigation increased, the amount of organic fertilizer relative decreased.

Therefore, a higher $\mathrm{pH}$ value of the land, should pay attention to soil improvement and selected appropriate physiological acid nitrogen, potassium and superphosphate acid fertilizer. At the same time, humic acid fertilizer application to reduce $\mathrm{pH}$ value is an effective way. Studies have shown that humic acid on soil acidification, which is conducive to the soil of alkaline tobacco plant growth and development and the formation of good quality.

\section{Acknowledgements}

This research was funded by Henan Tobacco Company Projects Grant (200903-02).

\section{References}

Chen, J.J., et al.: Effects of $\mathrm{pH}$ in Rhizosphere on the absorption of inorganic nutritions in tobacco. Plant Physiology Communications 32(5), 341-344 (1996)

Wang, Z.Q.: Geostatistics and its application in ecology. Science Press, Beijing (1999) 
Liu, X.M., et al.: Application of geostatistics and GIS technique to Characterize spatial variabilities of bioavailable micronutrients in paddys soils. Environmental geology 46, 189-194 (2004)

Lian, G., et al.: Spatial variability and prediction of soil nutrients in a small catchment of the loess plateau. Acta ecological snica 45(4), 577-584 (2008)

Wang, S.Y., et al.: Preliminary study on spttial variability and distribution of soil available microelements in Pinggu district of Beijing. Scientia agricultura sinica 28(10), 4957-4964 (2008)

Qin, Z.L., et al.: Spatial variability of $\mathrm{pH}$ and soil nutrient for planted tobacco leaf area in Guizhou Province. Chinese journal of soil science 38(6), 1046-1051 (2007)

Hou, J.R., et al.: Practical geological geostatistics, pp. 31-72. Geological Press, Beijing (1998)

Zhang, Q.L., et al.: Study on Spatial Distribution of Soil Quality and Quantitative Evaluation of Soil Fertility Quality under Middle Spatial Scale. Chinese Journal of Soil Science 34(6), 493-497 (2003)

Cambardella, C., et al.: Field-scale heterogeneity of soil properties in central Iowa soils. Soil Science Society of America Journal 58, 1501-1511 (1994)

Tang, L.N., et al.: Effect of soil acidity adjustment on growth and quality of tobacco. Journal of Fujian agricultural university 28(1), 71-76 (1999)

Chen, J.J., et al.: Studies on relationship of rhizospere $\mathrm{pH}$ value with yield and quality of FlueCured tobacco. Tropic subtropics soil science 5(2), 98-101 (1996) 